\title{
Deep vein thrombosis incidence in women diagnosed with breast cancer in brazil between 2007-2009
}

\author{
Daniele Medeiros Torres $^{1 *}$, Sabrina da Silva Santos ${ }^{2}$, Lais Goulart Cruz Baldanza ${ }^{1}$, Erica Nogueira Fabro ${ }^{1}$, Flavia Oliveira Macedo ${ }^{1}$, \\ Rejane Medeiros Costa ${ }^{1}$, Flavia Orind Ferreira ${ }^{1}$, Marianna Brito de Araujo Lou ${ }^{1}$, Rosalina Jorge Koifman ${ }^{2}$
}

Torres DM, Santos SS, Baldanza LGC, et al. Deep vein thrombosis incidence in women diagnosed with breast cancer in brazil between 2007-2009. J Phlebol Lymphol. 2018;11(1):36-41.

Background: Cancer may be linked to the risk of deep vein thrombosis, as well as cancer therapies, location and extent. In relation to breast cancer, the risk to develop venous thromboembolism (VTE) is 4 fold more when compared with patients of equivalent age without cancer.

Aims: To evaluate the incidence of deep vein thrombosis (DVT) in the cohort of women diagnosed with breast cancer, between 2007 and 2009, at the Brazilian National Cancer Institute (INCA).

Methods: A retrospective observational study in a hospital cohort of 4,413 women diagnosed with breast cancer between 2007-2009, and followed by 60 months. The databases were the hospital-based cancer registry of

\section{INTRODUCTION}

Breast cancer is the most common tumor location among women in the world. In Brazil, estimates for 2018 indicate the occurrence of about 59,700 new cases of breast cancer (ASR 56.33 cases per 100,000 women) [1]. Data from hospital records of cancer (HRC) in Brazil, including 59,317 women diagnosed with breast cancer between 2000 and 2009 , showed that $53.4 \%$ of these women were in advanced stages (2B: $15.9 \%$, 3A: $12.3 \%$, 3B: $14.7 \%, 3 \mathrm{C}: 1.7 \%, 4: 8.8 \%$ ) at diagnosis [2]. This advanced stage leads to the use of more aggressive treatments and various adverse effects resulting thereof [3].

Regarding systemic therapies, the main adverse effects found in cancer patients are cardiovascular disorders including myocardial ischemia, arrhythmia, pulmonary hypertension, peripheral arterial occlusive disease, pleural effusion and venous thromboembolism (VTE) [4]

VTE is a term that includes principally deep vein thrombosis (DVT) and pulmonary embolism (PE) [5]. Cancer is an important and independent risk factor for VTE [6], as well as the extent of the disease and their treatments [7]. From all VTE events that occur in the population, 18\% to $29 \%$ may be associated with cancer $[8,9]$.

In relation to breast cancer, It was reported, in a Danish cohort, that 8,586 women who had this diagnosis were 4 fold more likely to develop VTE compared with patients of equivalent age without cancer $(\mathrm{RR}=3.9 ; 95 \% \mathrm{Cl}$ 3.3-4.72) [10]. Chavez-MacGregor et al., in the United States, estimated a cumulative incidence of VTE of $2.9 \%$ in 12 months (1.4\% of DVT) among 89,172 women with breast cancer [11]. Moreover, based on data from a large cohort of the United Kingdom with 13,202 women with breast cancer, in the time following a VTE event, the risk of dying was more than doubled in multivariate analysis ( $\mathrm{HR}=2.42 ; 95 \%$ CI 2.13-2.75) [12].

Since breast cancer is the most frequent tumor site among women in the world [1], the occurrence of VTE, although low, represents an important Public Health problem, since it affects the prognosis of these women. Despite this, there are few epidemiological studies assessing the incidence
Brazilian National Cancer Institute - Cancer Hospital III and medical records. Outcome was defined as first episode of deep venous thrombosis, determined by Ultrasound Doppler. Cumulative incidence analyzes were performed using the survival functions by Kaplan-Meier method and Hazard ratios determined by Cox Regression.

Results: The conditional probability of developing deep vein thrombosis after diagnosis of breast cancer was $2.7 \%(\mathrm{n}=105)$ at 60 months of followup, and chemotherapy was the most important risk factor for DVT (adjusted HR=4.97; 95\% CI 2.68-9.21).

Conclusions: The incidence of deep vein thrombosis in this cohort of women diagnosed with breast cancer was low and remained relatively constant during the study time.

Key Words: Neoplasms; Breast neoplasms; Venous thrombosis; Incidence; Cohort studies.

of this adverse reaction in breast cancer patients and there are no registers of this incidence in Brazil. Furthermore, most evidences related to VTE, in patients with cancer, come from studies that combined pulmonary embolism and DVT as the outcome [13-15]. Such methodological decision introduce important limitations making impossible the understanding of the real DVT magnitude in cancer patients.

Therefore, the aim of this study was to evaluate the incidence of DVT in the cohort of women diagnosed with breast cancer between 2007-2009 at the Brazilian National Cancer Institute (INCA).

\section{METHODS}

\section{Study Population and Design}

This is a hospital cohort study with women diagnosed with breast cancer from January 2007 to December 2009 at the Cancer Hospital III of the National Cancer Institute (INCA), and retrospectively followed for 60 months.

All women diagnosed with breast cancer (ICD: C50.0-C50.9), aged at least 18 years, were eligible for the study.

During the study period, 4,641 histological confirmed breast cancer cases were identified using the Hospital-based cancer registry database of INCA Cancer Hospital III. Of these women, 228 (4.9\%) women were excluded with the following conditions: previous diagnosis of any cancer, a second primary tumor (except breast cancer) during the period of study, and diagnosis of DVT prior to breast cancer. Therefore, a cohort of 4,413 cases was formed to the analysis.

Data was obtained from computerized medical records and whenever necessary, physical records were consulted. The studied variables were: age and clinical stage at diagnosis; marital status; educational level; skin color; family history of cancer; history of alcohol and smoking consumption; surgery, radiation therapy, chemotherapy and hormonal

${ }^{1}$ Brazilian National Cancer Institute - INCA, Cancer Hospital III, Brazil

${ }^{2}$ National School of Public Health (ENSP), Oswaldo Cruz Foundation (FIOCRUZ), Brazil

*Correspondence: Torres DM, Brazilian National Cancer Institute - INCA, Cancer Hospital III, Brazil, E-mail: danieletorres_@hotmail.com; Doi: 10.14303/1983-8905.1000057

Received: August 13, 2018, Accepted: August 20, 2018, Published: August 28, 2018

This open-access article is distributed under the terms of the Creative Commons Attribution Non-Commercial License (CC BY-NC) (http:// creativecommons.org/licenses/by-nc/4.0/), which permits reuse, distribution and reproduction of the article, provided that the original work is properly cited and the reuse is restricted to noncommercial purposes. For commercial reuse, contact reprints@pulsus.com 
therapy start date. The occurrence of death and its date were collected and then confirmed through the information system mortality.

Outcome was determined using information system of the image department of INCA Cancer Hospital III. The first diagnosis of DVT, confirmed by Doppler Ultrasound from January 2007 to December 2014, was determined as outcome of interest.

\section{Statistical Analysis}

For descriptive analysis of the cohort, categorical variables were expressed as percentages and differences between them were analyzed using the chi-square test.

Incidence of deep vein thrombosis was analyzed considering DVT diagnosis as interest event, determined by the date of Doppler Ultrasound confirmation. The observation start time $\left(\mathrm{T}^{\circ}\right)$ was defined as the date of breast cancer clinical diagnosis. All living patients without a diagnosis of DVT were censored at the end of 60 months of follow-up and those lost during follow-up (for death) were censored at the last date recorded in the medical record and/or Mortality Information System. Cumulative incidences were estimated by Kaplan-Meier method, and the comparison of survival curves were performed using log-rank test $(95 \% \mathrm{CI})$.

A proportional Cox regression was also performed to determine the influence of different factors on risk of DVT, by crude and adjusted Hazard ratios and respective $95 \%$ confidence intervals $(95 \% \mathrm{CI})$. Multiple models were constructed using stepwise selection of variables with a $\mathrm{P}$ value $\leq 0.2$ at simple analysis. All variables with $p$ value less than 0.2 were tested in the model and remained in the final model those that were statistically significant or altered the estimates of other variables.

A $\mathrm{P}$ value $<0.05$ was used to ascertain the occurrence of statistical significance and all analyzes were performed with software SPSS version 20.0 (IBM Corporation, NY, USA).

\section{Ethical Aspects}

This study was approved by the Ethics Research Committees of all involved institutions (INCA and ENSP-FIOCRUZ).

\section{RESULTS}

The mean age of the 4,413 women with breast cancer, who composed this cohort, was 57 years (SD: 13.6; Median: 56); (data not shown) and 2.8\% of women with 60 years or more developed DVT. As well as $2.5 \%$ of nonwhite women, $2.4 \%$ of those that had less than eight years of schooling, $2.4 \%$ that had no partner, $2.4 \%$ of smokers, $2.3 \%$ of alcohol drinker and $2.6 \%$ of those that reported a family history of cancer. However, no difference statistically significant of such characteristics was observed among DVT positive and negative women (Table 1).

Considering clinical stage, the cumulative incidence of DVT increases with the increase of cancer staging, and the differences between groups was statistically significant $(\mathrm{P}=0.000)$; (Table 1$)$.

By comparing the groups of different therapeutic behaviors for the breast cancer, there was a statistically significant difference between the proportions of DVT diagnosis in relation to chemotherapy, surgery (mastectomy and breast-conserving surgery) and hormone therapy, with a higher proportion of DVT diagnosis in the groups without surgery $(4.2 \%)$, taking chemotherapy (3.3\%) and not using hormone therapy (3.2\%), than the groups with surgery $(3.0 \%)$, without chemotherapy $(0.9 \%)$ and using hormone therapy $(1.8 \%)$, respectively (Table 1$)$.

Deaths in five years occurred in $25.2 \%$ of women diagnosed with breas cancer and it was observed that a higher proportion of women in the group who developed DVT died (52.4\%) than the group with no DVT $(24.5 \%)$, and this difference was statistically significant $(\mathrm{P}=0.000)$; (Table 1$)$.

Table 1: Distribution of breast cancer cohort $(\mathrm{N}=4,413)$ according to socio demographic and clinical variables, Rio de Janeiro, Brazil, 2007-2009. (* Total differences occur by missing. ** For deaths, the totals are presented in the columns and not in the lines.

\begin{tabular}{lllllll}
\hline Variables & Without & DVT & Total & X2 P & Cumulativ & Log \\
& DVT & $N(\%)$ & $N(\%)$ & $\begin{array}{l}\text { valu } \\
\text { e }\end{array}$ & $\begin{array}{l}\text { Rank idence } \\
\text { (P) }\end{array}$ \\
& N (\%) & & & & $\begin{array}{l}\text { of DVT } \\
(\%)\end{array}$ &
\end{tabular}

$\begin{array}{clllll}\text { Age (yr.) } & & & & & \\ <45 & 781 & 19 & 800 & & 2.7 \\ & (97.6) & (2.4) & (100) & & \\ 45-59 & 1791 & 36 & 1827 & & 2.3 \\ & (98.0) & (2.0) & (100) & & \\ \geq 60 & 1736 & 50 & 1786 & 0.26 & 3.1 \\ & (97.2) & (2.8) & (100) & 3 & \end{array}$

Skin color*

White

$2408 \quad 55 \quad 2463$

$(97.8) \quad(2.2) \quad(100)$

Non-White

189

49

$(97.5)$

$49 \quad 1940$

(2.5) (100)

5

0.382

Education (yr.) $)^{\star}$

$\begin{array}{llllll}\leq 8 & 2780 & 68 & 2848 & & 2.7 \\ & (97.6) & (2.4) & (100) & & \\ >8 & 1514 & 36 & 1550 & 0.89 & 2.5 \\ & (97.7) & (2.3) & (100) & 2 & \end{array}$

0.696

Marital status*

$\begin{array}{llllll}\text { With a partner } & 1987 & 47 & 2034 & & 2.6 \\ & (97.7) & (2.3) & (100) & & \\ \text { Without a partner } & 2312 & 57 & 2369 & 0.83 & 2.7 \\ & (97.6) & (2.4) & (100) & 5 & \end{array}$

0.755

Smoking*

No\#

$2697 \quad 67 \quad 2764$

(97.6) (2.4) (100)

Current

1478
$(97.6)$

37

1515

$0.97 \quad 2.8$

0.892

Alcohol intake*

No\#\#

$2844 \quad 73 \quad 2917$

(95.5) (2.5) (100)

2.8

Current

1306

$31 \quad 1337$

(97.7)

(2.3)

(100)

$0.71 \quad 2.5$

8

0.653

Family history of cancer*

$\begin{array}{llllll}\text { No } & 1623 & 36 & 1659 & & 2.4 \\ & (97.8) & (2.2) & (100) & & \\ \text { Yes } & & & & & \\ & 2538 & 67 & 2605 & 0.40 & 2.9 \\ & (97.4) & (2.6) & (100) & 5 & \end{array}$

Clinical stage ${ }^{*}$

\begin{tabular}{|c|c|c|c|c|}
\hline $0-1 \mathrm{~A}$ & $\begin{array}{l}963 \\
(99.1)\end{array}$ & $9(0.9)$ & $\begin{array}{l}972 \\
(100)\end{array}$ & \\
\hline $2 A-2 B$ & $\begin{array}{l}153 \\
(98.1)\end{array}$ & $\begin{array}{l}30 \\
(1.9)\end{array}$ & $\begin{array}{l}1565 \\
(100)\end{array}$ & \\
\hline $3 A-3 C$ & $\begin{array}{l}1287 \\
(96.3)\end{array}$ & $\begin{array}{l}50 \\
(3.7)\end{array}$ & $\begin{array}{l}1337 \\
(100)\end{array}$ & \\
\hline 4 & $\begin{array}{l}430 \\
(96.4)\end{array}$ & $\begin{array}{l}16 \\
(3.6)\end{array}$ & $\begin{array}{l}446 \\
(100)\end{array}$ & $\begin{array}{l}0.00 \\
0\end{array}$ \\
\hline
\end{tabular}




\begin{tabular}{|c|c|c|c|c|c|c|}
\hline \multicolumn{7}{|l|}{ Surgery* } \\
\hline No & $\begin{array}{l}1071 \\
(95.8)\end{array}$ & $\begin{array}{l}47 \\
(4.2)\end{array}$ & $\begin{array}{l}1118 \\
(100)\end{array}$ & & 6.0 & \\
\hline Breast-conserving & $\begin{array}{l}892 \\
(99.0)\end{array}$ & $9(1.0)$ & $\begin{array}{l}901 \\
(100)\end{array}$ & & 1.0 & \\
\hline Mastectomy & $\begin{array}{l}2344 \\
(98.0)\end{array}$ & $\begin{array}{l}48 \\
(2.0)\end{array}$ & $\begin{array}{l}2392 \\
(100)\end{array}$ & $\begin{array}{l}0.00 \\
0\end{array}$ & 2.1 & 0.000 \\
\hline \multicolumn{7}{|l|}{ Radiation therapy* } \\
\hline No & $\begin{array}{l}2043 \\
(97.2)\end{array}$ & $\begin{array}{l}58 \\
(2.8)\end{array}$ & $\begin{array}{l}2101 \\
(100)\end{array}$ & & 3.1 & \\
\hline Yes & $\begin{array}{l}2264 \\
(98.0)\end{array}$ & $\begin{array}{l}46 \\
(2.0)\end{array}$ & $\begin{array}{l}2310 \\
(100)\end{array}$ & $\begin{array}{l}0.09 \\
3\end{array}$ & 2.3 & 0.032 \\
\hline \multicolumn{7}{|l|}{ Chemotherapy* } \\
\hline No & $\begin{array}{l}1609 \\
(99.1)\end{array}$ & $\begin{array}{l}14 \\
(0.9)\end{array}$ & $\begin{array}{l}1623 \\
(100)\end{array}$ & & 0.9 & \\
\hline Yes & $\begin{array}{l}2699 \\
(96.7)\end{array}$ & $\begin{array}{l}91 \\
(3.3)\end{array}$ & $\begin{array}{l}2790 \\
(100)\end{array}$ & $\begin{array}{l}0.00 \\
0\end{array}$ & 3.7 & 0.000 \\
\hline \multicolumn{7}{|l|}{ Hormonal therapy* } \\
\hline No & $\begin{array}{l}1746 \\
(96.8)\end{array}$ & $\begin{array}{l}57 \\
(3.2)\end{array}$ & $\begin{array}{l}1803 \\
(100)\end{array}$ & & 3.7 & \\
\hline Yes & $\begin{array}{l}2562 \\
(98.2)\end{array}$ & $\begin{array}{l}48 \\
(1.8)\end{array}$ & $\begin{array}{l}2610 \\
(100)\end{array}$ & $\begin{array}{l}0.00 \\
5\end{array}$ & 2.0 & 0.000 \\
\hline \multicolumn{7}{|l|}{ Death in 5 years ${ }^{* *}$} \\
\hline No & $\begin{array}{l}3253 \\
(75.5)\end{array}$ & $\begin{array}{l}50 \\
(47.6)\end{array}$ & $\begin{array}{l}3303 \\
(74.8)\end{array}$ & & 1.5 & \\
\hline Yes & $\begin{array}{l}1055 \\
(24.5)\end{array}$ & $\begin{array}{l}55 \\
(52.4)\end{array}$ & $\begin{array}{l}1110 \\
(25.2)\end{array}$ & $\begin{array}{l}0.00 \\
0\end{array}$ & 18.0 & 0.000 \\
\hline
\end{tabular}

\# Non-smoking include 11 former smokers, none of them developed DVT. \#\#No alcohol consumers include 4 former alcohol consumers, one of them developed DVT.)

Age $\geq 60(\mathrm{HR}=2.04 ; 95 \%$ CI $1.37-3.05)$ and chemotherapy $(\mathrm{HR}=4.97$; $95 \%$ CI 2.68-9.21) were associated with an increased risk of DVT, while surgery $(\mathrm{HR}=0.32 ; 95 \% \mathrm{CI} 0.20-0.51)$ and hormone therapy $(\mathrm{HR}=0.57$ $95 \%$ CI $0.38-0.85$ ) were associated with a decreased risk of developing DVT in the final model (adjusted by age, clinical stage, surgery, radiation therapy, chemotherapy and hormonal therapy). However, clinical stage $(\mathrm{HR}=2.13 ; 95 \%$ CI $1.01-4.49$, for $2 \mathrm{~A}-2 \mathrm{~B}$; $\mathrm{HR}=4.71 ; 95 \%$ CI $2.32-9.59$, for $3 \mathrm{~A}-3 \mathrm{C}$ and $\mathrm{HR}=8.21$; $95 \%$ CI $3.62-18.66$, for 4) and Radiation therapy (HR $=0.66$; $95 \%$ CI $0.45-0.97)$ were associated with increased and decreased risk of DVT, respectively, only in the unadjusted model (Table 2).

The overall cumulative incidence of DVT in 60 months of follow-up was $1.2 \%(\mathrm{n}=52)$ in 12 months, $1.8 \%(\mathrm{n}=73)$ in 24 months and $2.7 \%(\mathrm{n}=105)$ in 60 months (Table 3). Kaplan-Meier survival curves (Figure 1) using the log-rank test showed a significant difference in probabilities of developing DVT in 60 months, between groups, according to clinical stages, surgery, chemotherapy and hormone therapy.
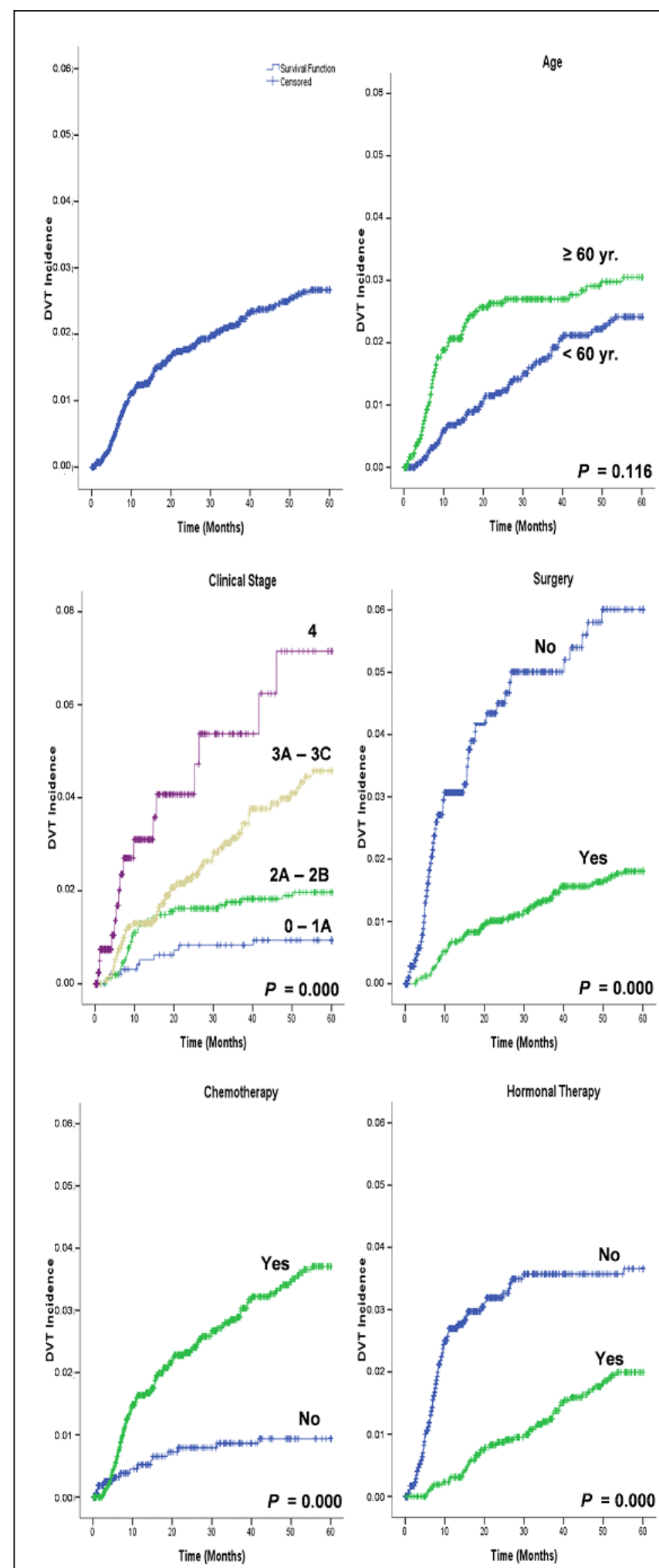

Figure 1: Cumulative incidence of deep vein thrombosis (DVT), in 60 months, Rio de Janeiro, Brazil, 2007-2009.

Table 2: Cumulative incidence of deep vein thrombosis (DVT), in 60 months, Rio de Janeiro, Brazil, 2007-2009.

$\begin{array}{llllllll}\text { Followin } & \mathrm{N}^{\circ} & \text { Case } & \text { Probabili } & \text { Probabili } & \text { Condition } & \text { Condition } & \text { Cumulati } \\ \mathrm{g} \text { time } & \text { at } & \mathrm{S} \text { of ty } & \text { of } & \text { ty of no } & \text { al } & \text { al } & \text { ve } \\ & \text { risk } & \text { DVT } & \text { DVT } & \text { DVT } & \text { probabilit } & & \text { incidence }\end{array}$




\begin{tabular}{|c|c|c|c|c|c|c|c|}
\hline${ }^{\text {(months }}$ & & & & & $\begin{array}{l}y \text { of no } \\
\text { DVT }\end{array}$ & $\begin{array}{l}\text { probabilit } \\
\text { y of DVT }\end{array}$ & $\begin{array}{l}\text { of } \\
(\%)\end{array}$ \\
\hline $0-6$ & $\begin{array}{l}4,41 \\
3\end{array}$ & 23 & 0.0052 & 0.9948 & 0.995 & 0.005 & 0.5 \\
\hline $6.1-12$ & $\begin{array}{l}4,19 \\
6\end{array}$ & 29 & 0.0069 & 0.9931 & 0.988 & 0.012 & 1.2 \\
\hline $\begin{array}{l}12.1 \\
18\end{array}$ & $\begin{array}{l}-4,01 \\
7\end{array}$ & 13 & 0.0032 & 0.9968 & 0.984 & 0.016 & 1.6 \\
\hline $\begin{array}{l}18.1 \\
24\end{array}$ & $\begin{array}{ll}- & 3,85 \\
& 5\end{array}$ & 8 & 0.0021 & 0.9979 & 0.982 & 0.018 & 1.8 \\
\hline $\begin{array}{l}24.1 \\
30\end{array}$ & $\begin{array}{l}-3,72 \\
3\end{array}$ & 8 & 0.0022 & 0.9978 & 0.980 & 0.020 & 2.0 \\
\hline $\begin{array}{l}30.1 \\
36\end{array}$ & $\begin{array}{l}-3,61 \\
7\end{array}$ & 5 & 0.0014 & 0.9986 & 0.979 & 0.021 & 2.1 \\
\hline $\begin{array}{l}36.1 \\
42\end{array}$ & $\begin{array}{l}3,51 \\
1\end{array}$ & 9 & 0.0026 & 0.9974 & 0.976 & 0.024 & 2.4 \\
\hline $\begin{array}{l}42.1 \\
48\end{array}$ & $\begin{array}{l}-3,42 \\
2\end{array}$ & 4 & 0.0012 & 0.9988 & 0.975 & 0.025 & 2.5 \\
\hline $\begin{array}{l}48.1 \\
54\end{array}$ & $\begin{array}{l}-3,36 \\
3\end{array}$ & 5 & 0.0015 & 0.9985 & 0.974 & 0.026 & 2.6 \\
\hline $\begin{array}{l}54.1 \\
60\end{array}$ & $\begin{array}{l}-3,29 \\
1\end{array}$ & 1 & 0.0003 & 0.9997 & 0.973 & 0.027 & 2.7 \\
\hline
\end{tabular}

Table 3: Hazard Ratio (HR) of deep vein thrombosis (DVT), in 60 months, Rio de Janeiro, Brazil, 2007-2009.

\begin{tabular}{|c|c|c|c|}
\hline \multirow{2}{*}{\multicolumn{2}{|c|}{ Variables }} & $\mathrm{HR}$ & Adjusted HR * \\
\hline & & $(95 \% \mathrm{Cl})$ & $(95 \% \mathrm{Cl})$ \\
\hline \multirow[t]{2}{*}{ Age (yr.) } & $<60$ & 1.00 & 1.00 \\
\hline & $\geq 60$ & $1.36(0.93-1.99)$ & $2.04(1.37-3.05)$ \\
\hline \multirow[t]{2}{*}{ Skin color } & White & 1.00 & \\
\hline & Non-White & $1.19(0.81-1.75)$ & \\
\hline \multirow[t]{2}{*}{ Education (yr.) } & $\leq 8$ & 1.00 & \\
\hline & $>8$ & $0.92(0.62-1.38)$ & \\
\hline \multirow[t]{2}{*}{ Marital status } & With a partner & 1.00 & \\
\hline & $\begin{array}{l}\text { Without a } \\
\text { partner }\end{array}$ & $1.06(0.72-1.57)$ & \\
\hline \multirow[t]{2}{*}{ Smoking } & Never smoker & 1.00 & \\
\hline & Smoker & $1.02(0.68-1.52)$ & \\
\hline \multirow[t]{2}{*}{ Alcohol intake } & Never & 1.00 & \\
\hline & Current & $0.95(0.62-1.43)$ & \\
\hline \multirow[t]{2}{*}{$\begin{array}{l}\text { Family history } \\
\text { cancer }\end{array}$} & No & 1.00 & \\
\hline & Yes & $1.16(0.77-1.73)$ & \\
\hline \multirow[t]{4}{*}{ Clinical stage } & $0-1 \mathrm{~A}$ & 1.00 & 1.00 \\
\hline & $2 A-2 B$ & $2.13(1.01-4.49)$ & $1.28(0.59-2.75)$ \\
\hline & $3 A-3 C$ & $4.71(2.32-9.59)$ & $2.07(0.96-4.48)$ \\
\hline & 4 & $\begin{array}{lll}8.21 & (3.62 & - \\
18.66) & & \end{array}$ & $1.69(0.65-4.44)$ \\
\hline
\end{tabular}

\begin{tabular}{llll}
\hline Surgery & No & 1.00 & 1.00 \\
& Yes & $0.27(0.18-0.40)$ & $0.32(0.20-0.51)$ \\
Radiation therapy & No & 1.00 & 1.00 \\
& Yes & $0.66(0.45-0.97)$ & $0.67(0.43-1.02)$ \\
Chemotherapy & No & 1.00 & 1.00 \\
& Yes & $3.89(2.21-6.82)$ & $4.97(2.68-9.21)$ \\
Hormonal therapy & No & 1.00 & 1.00 \\
& Yes & $0.49(0.33-0.71)$ & $0.57(0.38-0.85)$ \\
\hline
\end{tabular}

\section{DISCUSSION}

This study estimated the cumulative incidence of Deep Vein Thrombosis (DVT) in a cohort of 4,413 women diagnosed with breast cancer, from 2007 to 2009, at Cancer III Hospital (HCIII / INCA), and is the first study that estimates this incidence in a cohort of breast cancer women in Brazil.

In the literature, most studies combined pulmonary embolism and DVT incidences, making limited the information for comparisons to our findings. However, Chavez-MacGregor et al developed a retrospective cohort of breast cancer in USA population, analyzing the cumulative incidence of DVT, isolated from VTE, in incident cancer women. After 12 months of follow-up, the DVT incidence was $1.4 \%$ [11]. Similarly, we observed a cumulative incidence of $1.2 \%$ in 12 months of follow-up.

In relation to VTE cumulative incidence, a historical population cohort of 108,255 patients with breast cancer, in California, showed a VTE cumulative incidence of $1.2 \%$, after 2 years of follow-up, [13] a value below the DVT incidence reported in our study of $1.8 \%$ in the same follow-up period.

Some studies that analyze VTE cumulative incidence up to 60 months of follow-up. A population-based cohort that included 8,338 Swedish women diagnosed with invasive breast cancer, between 2001 and 2008, with a mean age of 57.1 years, observed, after a mean follow-up of 7.2 years, a VTE cumulative incidence at 1,2 and 5 years, of $2.0 \%, 2.5 \%$ and $4.0 \%$, respectively [16]. A value well above the result of our hospital-based cohort (2.7\% of DVT after 5 years). In contrast, Chew et al., using the Taiwan's National Health Insurance Research Database, identified 6,035 newly diagnosed breast cancer patients and a VTE cumulative incidence of $0.8 \%$ in more than 8 years of follow up [15].

VTE incidence in breast cancer is reported to be lower, when compared to some other cancers $[14,15]$. A study with a large population cohort $(n=235,149)$, after 2 years of follow-up, showed VTE cumulative incidence after a metastatic cancer diagnosis of pancreas (5.4\%), uterus $(4.8 \%)$, stomach $(4.4 \%)$ and bladder $(4.3 \%)$. In contrast, for metastatic breast cancer, VTE cumulative incidence was $2.6 \%$, one of the lowest incidences, except for metastatic cancers of lung $(2,4 \%)$, Non-Hodgkin lymphoma $(2,1 \%)$ and prostate $(1,2 \%)$ [17]. Although the low incidence of VTE in breast cancer, how breast cancer is the most frequent tumor site among women in the world, VTE in this population still represents an important Public Health problem, highlighting the importance of following the established thromboprophylaxis recommendations in this population [18].

Furthermore, a higher VTE incidence has been reported in specific groups of breast cancer women, according to the treatment received. In 2010, in a cohort of 280 women with early stage breast cancer who were treated with adjuvant chemotherapy at a UK cancer center, Nolan et al observed a cumulative VTE incidence of $7.5 \%$, during or up to four weeks after chemotherapy.[19] Onitilo et al reported a cumulative VTE incidence in American breast cancer women who underwent tamoxifen treatment (3435) of $8.4 \%$ (289), in a retrospective cohort between 1994 and 2009, with up to 5 years of follow-up.[8] These findings suggested that different therapeutic behaviors could alter the risk of a woman with breast cancer 
develop VTE. However, the risk factors associated with VTE, in breast cancer, were only adequately explored more recently.

In a recent cohort study of 13,202 English women diagnosed with breast cancer, Walker et al collected data from four different sources on population health care, between 1997 and 2006. Cases of VTE occurred in 611 women (8.4/ 1,000 person-years; 95\% CI 7.8 - 9.1), of which 314 were isolated DVT. The highest VTE absolute rates were observed during chemotherapy treatment and in the first month after the end of this treatment, with a risk of $10.8(95 \%$ CI $8.2-14.4)$ and $8.4(95 \% \mathrm{Cl}$ 4.9-14.2), respectively, when compared to women who did not undergo chemotherapy. The risk of VTE still increased with age in the multivariate analysis $(60-69$ years: $\mathrm{HR}=2.9,95 \%$ CI $1.8-4.6$ and 80 years: $\mathrm{HR}=$ $5.0,95 \%$ CI 3.0 - 8.2).[20]

Similarly, in our study, age was risk factor in multiple analyses and chemotherapy was the main risk factor for DVT. Although chemotherapy treatment is associated with an increased risk of thrombosis $[11,16,20]$, the pathogenic mechanisms for the thrombogenic effect of chemotherapeutic drugs are poorly understood [21]. Probably, chemotherapeutic agents are associated with thrombogenic mechanisms, such as reduction in fibrinolytic activity, direct endothelial cells lesions and interaction with the Von Willebrand factor [22].

Regarding the initiation of chemotherapy, Pritchard et al observed a predominance of $84 \%$ [21] of VTE cases occurring within 6 months after initiation of this treatment [23]. The prevalence of early VTE development was also observed in the prospective cohort of Kirwan et al, where of the 134 breast cancer women recruited prior to chemotherapy start, receiving clinical and radiological evaluations at 3, 6, 12, and 24 months of followup, 69\% developed VTE within 3 months of chemotherapy initiating [24]. In our cohort, for 91 DVT cases that realized chemotherapy, $42.9 \%$ of DVT diagnosis occurred within 6 months of the start of chemotherapy (data not shown).

Still in the study by Walker et al., it was observed that, in women who received hormone therapy, the risk of VTE, in the first three months after starting treatment, was more than double the risk compared to those women who did not undergo this therapy (HR=2.4, 95\% CI 1.7-3.4). But, no risk was observed after 3 months of hormone therapy (HR=0.9, $95 \%$ CI $0.7-1.1$ ), and only $3.7 \%$ of VTE cases had no indication of hormone therapy use [20].

In our study, for $30.5 \%$ of DVT cases, the estrogen and progesterone receptor status of the tumor was negative (data not shown), so, they had no indication for hormone therapy. This high frequency of negative hormone receptors tumors in women that developed DVT may explain our results that showed that the use of hormonal therapy was associated with a lower risk of developing DVT ( $\mathrm{HR}=0.57,95 \%$ CI $0.39-0.86$, in multiple analyses). However, in the study by Brand et al., hormonal therapy use was not statistically significant associated with a higher risk of developing VTE (HR=1.60, 95\% CI 0.87-2.94, adjusted for age at diagnosis). Moreover, Brand et al. observed that the negative status for progesterone hormone receptors was an independent risk factor for the development of VTE in women with breast cancer ( $\mathrm{HR}=1.38,95 \%$ CI 1.12-1.70, adjusted for age at diagnosis) but negative status for estrogen hormone receptors had no effect [16]. In contrast, in cohort of Chavez-MacGregor et al., with men and women breast cancers, negative status for estrogen hormone receptors was a protect factor for VTE $(\mathrm{OR}=0.84,95 \% \mathrm{CI} 0.73-0.96)$ and for DVT (OR=0.72, 95\% CI $0.59-0.88)$ in multiple analyses [11]. In our study, we could not analyze hormone receptors as a risk factor, because we do not have data on estrogen and progesterone receptor status for the women in the cohort that do not developed DVT.

Some biological mechanisms corroborate that hormonal therapy would be a risk factor for VTE, since, probably, the estrogenic effect of tamoxifen would lead to the reduction of antithrombin III [22], but in accordance with the above, this association still needs to be better studied.

An American database with 112,617 women undergoing surgical treatment of breast cancer between 2005 and 2013 observed a low risk of mortality and morbidities in these procedures, regardless of the age of the woman $(0.1 \%$ in women under 80 years and $0.3 \%$ in women aged 80 years or older, $\mathrm{p}<0.01$ ) [25]. In our study we found that the surgery procedures (mastectomy or a breast-conserving), was a protective factor for DVT. Similar result was found by Walker et al. demonstrating that surgical removal of the tumor is a protective factor for the development of DVT, although not statistically significant $(\mathrm{HR}=0.6,95 \% \mathrm{CI} 0.3-1.1)$, after the two month of hospital discharge [20].

Regarding radiotherapy, in multiple analysis, women in this study who underwent such treatment had no risk of developing DVT. In the Swedish population-based study that included 8,338 breast cancer patients, the radiotherapy showed no association with VTE in multivariable analyses (HR=1.07, 95\% CI 0.79-1.47) [16] Begtrupo et al. in a prospective clinical study evaluated blood sampling in 39 women who underwent adjuvant radiotherapy after breast cancer in the year 2016 at a Danish center and concluded that radiotherapy did not affect hemostasis evaluated by platelet aggregation and thrombin generation; neither as a single dose nor during the entire radiation course [26].

Another risk factor for VTE events is advanced staging of breast cancer, how was demonstrated in the cohort of Chavez-MacGregor et al. for VTE $(\mathrm{OR}=1.98,95 \%$ CI $1.68-2.33)$ and for DVT $(\mathrm{OR}=1.50,95 \% \mathrm{CI}$ 1.17-1.93), comparing stage 4 patients with stage 1 [11]. In our study, advanced staging of breast cancer was a risk factor for DVT only in the unadjusted model.

The current study was able to determine the incidence of DVT in a large hospital cohort, and to demonstrate some possible risk factors associated with DVT, mainly in relation to cancer treatment. The study has limitations pertinent to a retrospective study design. However, these limitations probably do not generate information bias, since the hospital has detailed patient records that were consulted by qualified and experienced professionals for the accomplishment of this study.

\section{CONCLUSIONS}

A cumulative incidence of deep venous thrombosis of $2.7 \%$ was found, after 60 months of follow-up, in the hospital cohort of women diagnosed with breast cancer from 2007 to 2009, and chemotherapy was the main risk factor.

\section{Conflict of Interest Disclosure}

Daniele Torres has nothing to disclose. Me and my institution did not receive payment or services from a third party for any aspect of the submitted work.

\section{REFERENCES}

1. Ferlay J, Soerjomataram I, Dikshit R, et al. Cancer incidence and mortality worldwide: Sources, methods and major patterns in GLOBOCAN 2012. Int J Cancer. 2015;136:359-86.

2. Abrahão KS, Bergmann A, Aguiar SS, et al. Determinants of advanced stage presentation of breast cancer in 87,969 Brazilian women. Maturitas. 2015;82:365-70.

3. Lee $\mathrm{BL}$, Liedke $\mathrm{PE}$, Barrios $\mathrm{CH}$, et al. Breast cancer in Brazil: present status and future goals. Lancet Oncol, 2012;13:95-102.

4. Aleman BM, Moser EC, Nuver J, et al. Cardiovascular disease after cancer therapy. EJC Suppl. 2014;12:18-28.

5. Streiff MB, Agnelli G, Connors JM, et al. Guidance for the treatment of deep vein thrombosis and pulmonary embolism. J Thromb Thrombolysis. 2016;41:32-67.

6. Farge D, Debourdeau P, Beckers M, et al. International clinical practice guidelines for the treatment and prophylaxis of venous thromboembolism in patients with cancer. Journal of Thrombosis and Haemostasis. 2013;11: 56-70.

7. Lee AY, Levine MN. Venous Thromboembolism and Cancer: Risks and Outcomes. Circulation. 2003;107:17-21.

8. Onitilo AA, Doi SA, Engel JM, et al. Clustering of venous thrombosis events at the start of tamoxifen therapy in breast cancer: a population-based experience. Thromb Res. 2012;130:27-31. 
9. Falanga A, Russo L. Epidemiology, risk and outcomes of venous thromboembolism in cancer. Hamostaseologie. 2012;32:115-25.

10. Cronin-Fenton DP, Søndergaard F, Pedersen LA, et al Hospitalisation for venous thromboembolism in cancer patients and the general population: a population-based cohort study in Denmark, 1997-2006. Br J Cancer. 2010;103: 947-53.

11. Chavez-MacGregor M, Zhao H, Kroll M, et al. Risk factors and incidence of thromboembolic events (TEEs) in older men and women with breast cancer. Ann Oncol. 2011;22:2394-02.

12. Khan UT, Walker AJ, Baig S, et al. Venous thromboembolism and mortality in breast cancer: cohort study with systematic review and meta-analysis. BMC Cancer. 2017;17:747.

13. Chew HK, Wun $T$, Harvey DJ, et al. Incidence of Venous Thromboembolism and the Impact on Survival in Breast Cancer Patients. J Clin Oncol. 2007;25:70-6.

14. Walker AJ, Card TR, West J, et al. Incidence of venous thromboembolism in patients with cancer - a cohort study using linked United Kingdom databases. Eur J Cancer. 2013;49:1404-13.

15. Chew TW, Gau CS, Wen YW, et al. Epidemiology, clinical profile and treatment patterns of venous thromboembolism in cancer patients in Taiwan: a population-based study. BMC Cancer. 2015;15:298-07.

16. Brand JS, Hedayati E, Bhoo-Pathy N, et al. Time-dependent risk and predictors of venous thromboembolism in breast cancer patients: A population-based cohort study. Cancer 2017; 123:468-75.

17. Chew HK, Wun T, Harvey DJ, et al. Incidence of Venous Thromboembolism and Its Effect on Survival Among Patients With Common Cancers. Arch Intern Med. 2006;166:458-64.

18. Andtbacka RH, Babiera G, Singletary SE, et al. Incidence and prevention of venous thromboembolism in patients undergoing breast cancer surgery and treated according to clinical pathways. Ann Surg. 2006;243:96-01.

19. Nolan L, Darby A, Boleti K, et al. The incidence of symptomatic thromboembolism in patients receiving adjuvant anthracycline-based chemotherapy of early stage breast cancer. Breast. 2011;20:151-54.

20. Walker AJ, West J, Card TR, et al. When are breast cancer patients at highest risk of venous thromboembolism? A cohort study using English health care data. Blood. 2016;127:849-57.

21. Woodley-Cook J, Shin LY, Swystun L, et al. Effects of the chemotherapeutic agent doxorubicin on the protein $\mathrm{C}$ anticoagulant pathway. Mol Cancer Ther. 2006;5:3303-311.

22. Levine MN, Gent M, Hirsh J, et al. The thrombogenic effect of anticancer drug therapy in women with stage II breast cancer. N Engl J Med. 1988;318:404-07.

23. Pritchard KI, Paterson AH, Paul NA, et al. Increased thromboembolic complications with concurrent tamoxifen and chemotherapy in a randomized trial of adjuvant therapy for women with breast cancer. National Cancer Institute of Canada Clinical Trials Group Breast Cancer Site Group. J Clin Oncol. 1996;14: 273137.

24. Kirwan CC, Mcdowell G, Mccollum CN, et al. Incidence of Venous Thromboembolism during Chemotherapy for Breast Cancer: Impact on Cancer Outcome. Anticancer Res. 2011;31:2383-88.

25. Pettke E, Ilonzo N, Ayewah M, et al. Short-term, postoperative breast cancer outcomes in patients with advanced age. Am J Surg. 2016;212:677-81.

26. Begtrup KM, Hojbjerg JA, Offersen BV, et al. Adjuvant radiotherapy does not affect hemostasis. Platelets. 2018;29:1-9. 